\title{
Physical stability of moisture-sensitive tablets stored in canister or as unit-dose
}

Kathrin Bjerknes ${ }^{1}$, Zahra Helmizadeh ${ }^{2}$, Jørgen Brustugun ${ }^{1}$ and Gro Smistad ${ }^{2 *}$

${ }^{1}$ Hospital Pharmacies Enterprise, South Eastern Norway, Norway

${ }^{2}$ School of Pharmacy, University of Oslo, Norway

Qualifications and title of the authors (surname underlined):

Kathrin Bjerknes: PhD, Chief Pharmacist

Zahra Helmizadeh: MPharm, Master student

Jørgen Brustugun: PhD, Research scientist

Gro Smistad: PhD, Professor

\section{Keywords:}

Repackaging, unit-dose, humidity, physical stability, tablets

\section{*Corresponding author:}

Gro Smistad, School of Pharmacy, University of Oslo, P.O.Box 1068 - Blindern, N-0316 Oslo, Norway, E-mail: gro.smistad@farmasi.uio.no 


\section{ABSTRACT}

Background: Knowledge about the long-term stability of oral drug products outside the original container, e.g. as unit-doses, is limited. This leaves the pharmacist with the dilemma of seeking improved patient safety by use of unit-doses on one side, versus the lack of knowledge about the stability of the repackaged drug on the other.

Aim: To screen the physical stability of moisture-sensitive repackaged tablets to identify candidates with the need for further chemical stability testing.

Method: The physical stability of commercially available tablets (16 products) was investigated after six months of storage at ambient conditions in canisters for unit-dose production and after three months of storage as unit-doses in a climate chamber at $25^{\circ} \mathrm{C} / 60 \%$ RH. Changes in appearance, colour and mass were investigated in addition to changes in disintegration time, friability, and resistance to crushing.

Results: The appearance and results of the physical tests for all products were acceptable and within the requirements of the European Pharmacopoeia, except for the enteric coated tablets containing sodium valproate (Orfiril). These tablets were significantly altered after three months of storage as unit-doses at $25^{\circ} \mathrm{C} / 60 \% \mathrm{RH}$. However, when stored at ambient conditions the tablets complied with the tests.

Conclusions: The current study was a screening study limited to investigation of physical stability of a selection of moisture-sensitive repackaged tablets. However, although the physical stability is acceptable, the chemical stability and dissolution rate may be altered. The physical tests outlined are simple but could be suitable for selecting candidates for further chemical stability testing. 


\section{INTRODUCTION}

Repackaging of tablets into unit-doses is expected to improve patient safety since the tablet is fully identifiable until the moment of administration. However, such a practice increases the need for knowledge regarding stability of tablets outside the original packaging. Although commercial service providers commonly practice repackaging of drugs, knowledge about long-term stability of oral drug products outside the original container is limited. The drug manufacturers have few, if any, requirements from the authorities to provide such information ${ }^{1}$, and there are few scientific publications covering this subject. The pharmacist is therefore often left with the dilemma through lack of knowledge about the stability of the repackaged drug on one hand, versus obtaining improved patient safety on the other.

However, some authorities, like the Swedish Medicinal Agency, provide information on the product stability outside the original bulk packaging after dose dispensing. The information is based on documentation from the manufacturers. Also, a list based on information from drug manufacturers has been presented by Church et al. covering 392 products $^{2}$. The Food and Drug Administration laboratories have performed some studies to provide further knowledge regarding the effect of repackaging ${ }^{3-5}$. In one of these works, furosemide tablets were chosen as model drug due to its moisture sensitivity ${ }^{3}$.

In a review by Waterman, the stability of drugs by packaging with respect to moisture protection is described ${ }^{6}$. The relative humidity inside the packaging was described as important to physical stability. This is in line with other studies finding that changes in physical stability are significant when tests are performed at the accelerated conditions outlined in the guidelines of the International Conference on Harmonization (ICH) $\left(40^{\circ} \mathrm{C} / 75 \% \mathrm{RH}\right)$, while no change is seen when tests are performed at the long-term conditions $\left(25^{\circ} \mathrm{C} / 60 \% \mathrm{RH}\right)^{4} 578$.

Another change seen in some products after repackaging is discolouration ${ }^{9-11}$. The authors are concerned by the effect a change in appearance may have on compliance. Possible formation of toxic photodegradants is another issue associated with discolouration. Glass et al consider this to be critical when prochloroperazine tablets are becoming grey ${ }^{10}$. Despite the confirmation of physical and chemical stability within the British Pharmacopoeial limits, the discoloration and the potential for photodegradants to cause adverse effects in patients led the authors to conclude that the quality of the tablets had been compromised. A situation similar/comparable to unit-dose repackaging is the use of dosage administration aids. An 
overview of stability studies performed on medicines in such aids can be found in a review paper by Tan and Kwan ${ }^{12}$. However, there is still a need for more investigations to assess the shelf lives of moisture-sensitive drugs after repackaging.

The aim of the current study was to focus on the physical stability after unit-dose production of several oral drugs with known issues regarding moisture sensitivity according to the SPC. Although physical changes say nothing about changes in the amount of drug or drug release from the tablet, physical instability itself may make the product unusable. Since physical tests are easy to perform and make screening of a large amount of products possible, products may be excluded from unit-dose packaging early in the process without time consuming chemical tests. Also, moderate changes in physical properties may indicate changes in drug content and dissolution rate, and may point out which products should be studied more carefully by chemical tests.

\section{METHODS}

\section{Materials}

The drug products included in this study were all obtained from commercial sources and are listed in Table 1. The chemicals used for the disintegration testing were di-sodium hydrogen phosphate dihydrate, citric acid monohydrate and $12 \mathrm{M}$ hydrochloric acid (37\%) from Merck GmbH (Germany).

\section{Repackaging of the tablets}

The repackaging of the tablets was performed in the hospital pharmacy production facility (Akershus University Hospital, Norway). The tablets were manually transferred, by using gloves, from the original containers into bulk storage canisters in class D facilities. For unitdose production, canisters containing the drug products were transferred into a SwissLog PillPick system (SwissLog AG, Switzerland) in which the unit-doses were produced. Each unit-dose consisted of a single tablet in a labelled, bar-coded, heat-sealed plastic bag. The packaging material (A000015 from SwissLog GmbH, Germany) complied with USP Class C packaging material ${ }^{13}$. The bags were made from biaxially oriented polypropylene (BOPP) film co-extruded on both sides with polyolefinic copolymers. The thickness of the film was 40 
$\mu \mathrm{m}$. The canisters were stored for not more than two days at room temperature in the facility area at the hospital pharmacy prior to unit-dose production.

\section{Stability study}

Bulk samples of 300 tablets per canister (one canister for each drug product), unit-doses (approximately 100 bags of each drug product) and reference samples of each product (i.e. the drug product in the original container from vendor) were included in the study. All samples were stored protected from light. The reference samples were investigated at time zero.

\section{Storage at ambient conditions}

Bulk tablets in canister were stored at ambient temperature and humidity in the production facility at the hospital pharmacy and were investigated for physical stability after both three and six months. In addition, unit-doses of a modified-release formulation and a gastroresistant formulation of sodium valproate (Orfiril Retard and Orfiril $300 \mathrm{mg}$ enterotablets) were included in the study and investigated after three months of storage in the SwissLog PillPick system to illustrate the stability under actual "in process" conditions. The temperature in the production facility was aimed to be in the range $22-23{ }^{\circ} \mathrm{C}$ and was continually monitored throughout the study by FMS Isoair Plus ${ }^{\circledR}$ (Malvern Instruments Ltd, Malvern, England), the humidity level in the range $35-45 \% \mathrm{RH}$.

\section{Storage at controlled conditions $\left(25^{\circ} \mathrm{C} / 60 \% \mathrm{RH}\right)$}

Unit-doses of all the preparations were stored in a climate chamber at $25^{\circ} \mathrm{C} / 60 \% \mathrm{RH}$ (Binder, KBF 720, Binder GmbH, Tuttlingen, Germany). This is the general conditions for long-term storage in Mediterranean climatic zone in the ICH guidelines ${ }^{1}$. The samples were investigated for physical stability after three months.

\section{Tablet characterization}

After storage the tablets were visually inspected and tested for colour change in the $\mathrm{L}^{*} \mathrm{a}^{*} \mathrm{~b}^{*}$ colour space (CIELAB) using in a Minolta spectrophotometer, Model CM-3500d (Minolta Co LTD, Osaka, Japan). The total CIELAB colour difference $\left(\Delta \mathrm{E}^{*}{ }_{\mathrm{ab}}\right)$ was determined as $\Delta \mathrm{E}^{*}{ }_{\mathrm{ab}}$ 
$=\sqrt{(\Delta L *)^{2}+(\Delta \mathrm{a} *)^{2}+(\Delta \mathrm{b} *)^{2}}$, where $\Delta \mathrm{L}^{*}, \Delta \mathrm{a}^{*}$ and $\Delta \mathrm{b} *$ indicates change in the brightness, red-green and yellow-blue directions, respectively, compared with the reference samples measured at time point zero. Three tablets from each batch were measured at each time point, and the colour was measured at three different areas on each tablet.

The samples were also tested for uniformity of mass (Ph.Eur.2.9.5) ${ }^{14}$ and average change in mass using a Mettler-Toledo AG204 DeltaRange balance (Mettler-Toledo GmbH, Greifensee, Swirzerland), resistance to crushing (Ph.Eur.2.9.8) ${ }^{15}$ using Erweka TBH 125 Hardness tester (Erweka GmbH, Heussenstamm, Germany), friability (Ph.Eur.2.9.7) ${ }^{16}$ using Erweka TA Friability tester (Erweka GmbH, Heussenstamm, Germany) and disintegration (Ph.Eur.2.9.1) ${ }^{17}$. However, the disintegration test equipments (ERWEKA ZT 3-2 and ZT 220 Disintegration Testers, ERWEKA GmbH, Heusenstamm, Germany) were not suitable for some of the products due to large size (Renvela) or the formulation characteristics (fast disintegrating tablets with embedded enteric coated pellets; Losec 10 and $20 \mathrm{mg}$, and Nexium 20 and $40 \mathrm{mg}$ ). The following method was applied for these products: Three tablets were placed in a $250-\mathrm{mL}$ beaker containing distilled water $\left(36-38^{\circ} \mathrm{C}\right)$. The beaker was swirled gently by hand, and the time when all tablets had disintegrated was recorded manually ${ }^{18}$.

\section{Statistical methods}

Comparison of the results was performed by analysis of variance (ANOVA) followed by Tukey's Post Hoc test. The values after three and six months of storage were compared with the values at time point zero. The level of significance used was $\mathrm{p}<0.05$ (Minitab 16 statistical software, Minitab Inc., Pennsylvania, USA)

\section{RESULTS}

The colour, average tablet weight and average resistance to crushing of all the products at the start of the study are listed in Table 1. During the study the temperature in the production and storage facilities was room temperature typically in the range $21-23{ }^{\circ} \mathrm{C}$; never below $15^{\circ} \mathrm{C}$ and never above $25^{\circ} \mathrm{C}$, monitored continuously by the FMS-system. 


\section{Appearance and colour change}

The visual appearance after storage in canister for six months at ambient conditions were unchanged for all samples, and also for most tablets stored for three months as unit-dose under controlled conditions $\left(25^{\circ} \mathrm{C} / 60 \% \mathrm{RH}\right)$. The only exceptions were unit-doses of the gastro-resistant formulations of sodium valproate (Orfiril $150 \mathrm{mg}, 300 \mathrm{mg}$ and $600 \mathrm{mg}$ ). These tablets had several holes and cracks in the coating (Figure 1). Also, the white colour became darker. This was confirmed spectrophotometrically with relatively large $\Delta \mathrm{E}^{*}$ ab values of these tablets (6.1, 9.0 and 6.4, respectively, for Orfiril $150 \mathrm{mg}, 300 \mathrm{mg}$ and $600 \mathrm{mg}$ ) as compared to the other tablets where all samples except Renvela, showed no visual colour change and $\Delta \mathrm{E}^{*}{ }_{\mathrm{ab}}<3$ (data not shown). Renvela had $\Delta \mathrm{E}^{*}{ }_{\mathrm{ab}}$ of 3.1 and a slightly yellow colour could be observed. It is worth noting that the appearance and the colour of the sodium valproate tablets stored as unit-doses at ambient conditions within the SwissLog PillPick system were unchanged with a $\Delta \mathrm{E}^{*}{ }_{\mathrm{ab}}$ value of 1.1 .

\section{Physical characteristics}

\section{Uniformity of mass and average change in mass}

The changes in mass after storage for all the samples are shown in Figure 2. The average change in mass was less than $5 \%$ for all samples stored at ambient conditions in canister and for most of the tablets stored as unit-doses at $25^{\circ} \mathrm{C} / 60 \% \mathrm{RH}$. The only exceptions were the gastro-resistant formulations of sodium valproate (Orfiril $150 \mathrm{mg}, 300 \mathrm{mg}$ and $600 \mathrm{mg}$ ) and the film coated tablets with sevelamer carbonate (Renvela) stored as unit-doses at $25^{\circ} \mathrm{C} / 60 \%$ RH. These preparations had a weight increase in the range 10-15\%. However, Orfiril $150 \mathrm{mg}$ was the only product which did not comply with the test Uniformity of mass (Ph.Eur.2.9.5) ${ }^{14}$ after the storage period.

\section{Resistance to crushing}

Figure 3 shows the $\%$ change in resistance to crushing. For the tablets stored for six months in canister at ambient conditions, only six of the products (TrioBe, Nexium 20 and $40 \mathrm{mg}$, Cytotec $0.2 \mathrm{mg}$ and Losec 10 and $20 \mathrm{mg}$ ) had a significant change in resistance to crushing. The change was relatively low ( $<15 \%$ reduction). When stored as unit-doses at $25^{\circ} \mathrm{C} / 60 \%$ RH the change was larger, typically $25-40 \%$ decrease. The largest change in resistance to crushing was seen for the sodium valproate enterotablets (Orfiril) stored as unit-doses at 
$25^{\circ} \mathrm{C} / 60 \% \mathrm{RH}$ with a decrease in the range $75-90 \%$ of the initial value. On the other hand, the modified-release tablets of sodium valproate (Orfiril Retard) became harder after storage as unit-doses at these conditions. However, when stored as unit-doses for three months at ambient conditions in the PillPick system no significant change was observed neither for the Orfiril 300 mg enterotablets nor the Orfiril Retard.

\section{Friability and disintegration}

All products complied with Ph.Eur. friability requirements ${ }^{16}$, with a maximum loss of $0.4 \%$ (data not shown). All preparations also complied with the test for disintegration ${ }^{17}$, except for the gastro-resistant formulations of sodium valproate stored as unit-doses at $25^{\circ} \mathrm{C} / 60 \% \mathrm{RH}$. As mentioned already these tablets lost their integrity during storage under these conditions, as seen in Figure 1.

\section{DISCUSSION}

Repackaging of tablets into unit-dose containers provides patient safety by reducing errors in handling of the medicines. However, the quality of the tablets may be compromised when removed from the original container. The shelf life of the product given by the manufacturer is based on storage in the original container. In daily life, however, the tablets may be stored for months outside the original container when manufactured as unit-doses or dispensed in multicompartment compliance aids. During such storage it is likely that the shelf life can be affected both by the varying environment and by the varying characteristics of the immediate repackaging material and container. The knowledge regarding the tablet stability in such situations is limited, and more studies to document the stability are required ${ }^{19}$.

The current study was carried out to provide increased knowledge about the physical stability of repackaged tablets within the hospital pharmacy. Although all products included in this study were moisture sensitive according to the SPC, only the Orfiril gastro-resistant formulations were severely affected by the humid conditions when stored as unit-doses at 25 ${ }^{\circ} \mathrm{C} / 60 \% \mathrm{RH}$. When stored at ambient conditions in the production facility, however, both the colour and the mechanical strength were unchanged also for these tablets. This means that the 
humidity when storing these tablets is potentially critical and the product is perhaps not the best candidate for unit-dose production.

A change in visual appearance may influence the patient compliance and make the product unacceptable for use, ${ }^{9-11}$ regardless of changes or not in the drug content. A combination of visual inspection and instrumental measurement was used for detecting colour change in this study. There are no formal acceptance criteria regarding the spectrophotometric colour change test, but a value of two for $\Delta \mathrm{E}^{*}$ ab has previously been suggested as a tolerance limit for visible changes for film coated tablets of ofloxacin ${ }^{20}$. In the present study the highest value measured for tablets with no visual colour change was $\Delta \mathrm{E}^{*}{ }_{\mathrm{ab}}=3.38$ (Losec Mups $20 \mathrm{mg}$; pink tablets), while the lowest value visible by eye was $\Delta \mathrm{E}^{*}{ }_{\mathrm{ab}}=3.13$ (Renvela; white tablets turning into slightly yellow). Since visible colour change depends both on colour and direction of colour change ${ }^{20}$, the discrepancies could be caused by different colours of the tablets.

Another physical parameter which could make the tablets unsuitable for use is change in the mechanical strength. It is reasonable to assume that the mechanical strength could be affected by water absorption, which would also result in an increase in weight. A weight increase was, indeed, evident for a large number of the unit-doses stored for three months at $25^{\circ} \mathrm{C} / 60 \%$ (Figure 2). This may be explained by diffusion of water molecules through the plastic film of the unit-dose bag - a phenomenon confirmed by testing the weight increase of samples of dried silica in unit-dose bags stored at humid conditions. A significant decrease in resistance to crushing was found for the tablets increasing in mass. Including tablets with weight increase $>1 \%$, a correlation between weight increase $(\%)$ and reduction in resistance to crushing $(\%)$ was seen $\left(r^{2}=0.967\right)$. However, although the resistance to crushing changed significantly, it was still deemed as acceptable for most of the products and the friability was low $(<0.4 \%)$. The only exception was the gastro-resistant formulations containing sodium valproate (Orfiril $150 \mathrm{mg}, 300 \mathrm{mg}$ and $600 \mathrm{mg}$ ). These tablets had the highest weight increase and became very soft, which is also in accordance with studies in the literature on physical stability of sodium valproate tablets repackaged into dose administration aids ${ }^{78}$. In the current study only one type of plastic material was used for the unit-dose production. Other materials may of course have different barrier properties. Also, only one type of canister was used in this study; other types of canisters may have different properties. However, for all types of canisters the tablets are removed from the original container and are thereby exposed to the surrounding environment. It is reasonable to expect that the tablet properties will be 
influenced both by the internal environment in the canisters, but also by the barrier properties of the canister material, the climate, the season of the year and the filling level of the canister.

To summarize; all products included in this study were moisture-sensitive according to the manufacturers. The results show that the physical changes during storage outside the original container were minor for most of the products included in the study, both when stored at the ambient conditions in the production facility and as unit-doses at higher humidity $\left(25^{\circ} \mathrm{C} / 60 \%\right.$ $\mathrm{RH})$. The limitation of the study, however, was that no chemical investigations were conducted. When water is present, chemical stability and changes in the dissolution rate become questions of particular concern. The physical tests outlined in this paper are easy to perform and within the reach of what can be performed in a hospital pharmacy. The tests may be used as a rational first step to exclude candidates for unit-dose packaging if the appearance or the mechanical strength is severely affected. Also, the tests could be used for selection of tablets of particular concern for further chemical stability testing. The physical stability of a dosage form and the chemical stability may not align, as demonstrated by Llewelyn et al. for sodium valproate tablets repackaged into dose administration aids ${ }^{7}$. However, a combination of large changes in mechanical strength and weight increase indicate the need for further investigation of changes in dissolution rate and chemical instability.

\section{REFERENCES}

1. ICH Harmonised Tripartite Guideline. Stability testing of new drug substances and products O1A(R2). Geneva: ICH Steering Committee, 2003.

2. Church $\mathrm{CaS}$, J. How stable are medicines moved from original packs into compliance aids? The Pharmaceutical journal 2006;276:7.

3. Asafu-Adjaye EB, Carlin AS, Jefferson EH, et al. Comparative stability study of unit-dose repackaged furosemide tablets. Clinical Research and Regulatory Affairs 2011;28(2):38-48. doi: doi:10.3109/10601333.2011.568492

4. Gupta A, Ciavarella AB, Rothman B, et al. Stability of gabapentin 300-mg capsules repackaged in unit dose containers. Am J Health-Syst Pharm 2009;66(15):1376-80. doi: 10.2146/ajhp080236

5. Yang YS, Gupta A, Carlin AS, et al. Comparative stability of repackaged metoprolol tartrate tablets. Int J Pharm 2010;385(1-2):92-97. doi: 10.1016/j.ijpharm.2009.10.040

6. Waterman KC, MacDonald BC. Package Selection for Moisture Protection for Solid, Oral Drug Products. J Pharm Sci 2010;99(11):4437-52. doi: 10.1002/jps.22161

7. Llewelyn VK, Mangan MF, Glass BD. Stability of sodium valproate tablets repackaged into dose administration aids. J Pharm Pharmacol 2010;62(7):838-43. doi: 10.1211/jpp.62.07.0004

8. Redmayne N, Robertson S, Kockler J, et al. Repackaged sodium valproate tablets - Meeting quality and adherence to ensure seizure control. Seizure-European Journal of Epilepsy 2015;31:10811. doi: 10.1016/j.seizure.2015.07.007 
9. Bowen L, Mangan, M., Haywood, A. and Glass, BD. Stability of Furosemide Tablets Repackaged in Dose Administration Aids. Journal of Pharmacy Practice and Research 2007;37(3):4. [published Online First: 181]

10. Glass B, Mangan M, Haywood A. Prochlorperazine tablets repackaged into dose administration aids: can the patient be assured of quality? Journal of Clinical Pharmacy and Therapeutics 2009;34(2):161-69. doi: 10.1111/j.1365-2710.2008.00981.x

11. Yamazaki N, Taya K, Shimokawa K, et al. Corrigendum to: The most appropriate storage method in unit-dose package and correlation between color change and decomposition rate of aspirin tablets (vol 396, pg 105, 2010). Int J Pharm 2011;404(1-2):325-30. doi: 10.1016/j.ijpharm.2010.11.033

12. Tan JZY, Kwan YH. Stability of chronic medicines in dosage administration aids. How much have been done? Saudi Pharmaceutical Journal 2014(0):8. doi: http://dx.doi.org/10.1016/i.jsps.2014.02.002

13. USP-NF $<671>$ Containers-Permeation. http://www.pharmacopeia.cn/v29240/usp29nf24s0 c671.html: U.S.Pharmacopoeia 29.

14. European Pharmacopoeia Online 8.7 - 2.9.5. - Uniformity of mass of single-dose preparations. http://online6.edqm.eu/ep807/: The European Directorate for the Quality of Medicines and HealthCare, 2016.

15. European Pharmacopoeia Online 8.7 - 2.9.8. - Resistance to crushing of tablets

http://online6.edqm.eu/ep807/: The European Directorate for the Quality of Medicines and HealthCare

2016.

16. European Pharmacopoeia Online 8.7 - 2.9.7 Friability of uncoated tablets.

http://online6.edqm.eu/ep807/: The European Directorate for the Quality of Medicines and HealthCare, 2016.

17. European Pharmacopoeia Online 8.7 - 2.9.1. Disintegration of tablets and capsules. http://online6.edqm.eu/ep807/: The European Directorate for the Quality of Medicines and HealthCare, 2016.

18. Farmakopékommisjonen Dd. Pharmacopoea Nordica, Editio Danica. Copenhagen, Denmark: Nyt Nordisk Forlag Arnold Busck 1963:341.

19. Gilmartin JF-M, Raimi-Abraham BT, Jani Y, et al. Taking the guesswork out of supplying multicompartment compliance aids: do pharmacists require further guidance on medication stability? International Journal of Pharmacy Practice 2015:n/a-n/a. doi: 10.1111/ijpp.12183

20. Tonnesen HH, Brunsvik A, Loseth $\mathrm{K}$, et al. Photoreactivity of biologically active compounds. XVIII. Photostability of ofloxacin in the solid state and in a tablet formulation. Pharmazie 2007;62(2):105-11. doi: 10.1691/ph.2007.2.5184 


\section{FIGURE CAPTIONS}

\section{Figure 1}

Visual appearance of gastro-resistant tablets containing sodium valproate after three months of storage as unit-doses at $25^{\circ} \mathrm{C} / 60 \%$ RH. a) Orfiril $150 \mathrm{mg}$ b) Orfiril $300 \mathrm{mg}$

\section{Figure 2}

Average change in mass in per cent of the reference sample average mass after storage at different conditions as bulk in canister or as unit-doses $(n=20)$. Error bars represent standard deviations

\section{Figure 3}

Change in resistance to crushing in per cent of the reference sample for tablets stored as bulk in canisters in the production facility or as unit-doses at $25^{\circ} \mathrm{C} / 60 \% \mathrm{RH}(\mathrm{n}=10)$. * the values were outside the range of the instrument $(>300 \mathrm{~N})$. All individual tablets were within the range indicated by the error bars. 
Table 1

Overview of the products included in the study and characteristics of the tablets

\begin{tabular}{|c|c|c|c|c|}
\hline Product & Active ingredient & Colour & $\begin{array}{l}\text { Initial tablet } \\
\text { weight }(n=20) \\
\mathrm{mg} \pm \text { SD (\%) }\end{array}$ & $\begin{array}{l}\text { Initial resistance } \\
\text { to crushing }(n=10) \\
\text { Average (Range) }\end{array}$ \\
\hline Atacand $4 \mathrm{mg}^{*}$ & Candesartan cilexetil & White & $129 \mathrm{mg} \pm 1.6 \%$ & $72 \mathrm{~N}(59-79)$ \\
\hline Atacand $16 \mathrm{mg}^{*}$ & Candesartan cilexetil & Pink & $129 \mathrm{mg} \pm 0.7 \%$ & $71 \mathrm{~N}(65-77)$ \\
\hline Cozaar $12.5 \mathrm{mg}^{\dagger}$ & Losartan potassium & Yellow $^{\dagger+}$ & $78 \mathrm{mg} \pm 1.0 \%$ & 54 N (49-61) \\
\hline Cozaar $50 \mathrm{mg}^{\dagger}$ & Losartan potassium & White $^{+\dagger}$ & $154 \mathrm{mg} \pm 0.8 \%$ & 112 N (101-119) \\
\hline Cytotec $0.2 \mathrm{mg}^{\ddagger}$ & Misoprostol & White & $200 \mathrm{mg} \pm 0.7 \%$ & 181 N (168-194) \\
\hline Diovan $80 \mathrm{mg}^{\S}$ & Valsartan & Pink $^{\dagger+}$ & $162 \mathrm{mg} \pm 2.1 \%$ & $93 \mathrm{~N}(78-110)$ \\
\hline Losec MUPS $10 \mathrm{mg}^{*}$ & Omeprazole & Pink $^{+\dagger}$ & $254 \mathrm{mg} \pm 1.0 \%$ & 165 N (152-179) \\
\hline Losec MUPS $20 \mathrm{mg}^{*}$ & Omeprazole & Pink $^{+\dagger}$ & $334 \mathrm{mg} \pm 0,9 \%$ & $210 \mathrm{~N}(187-226)$ \\
\hline Nexium $20 \mathrm{mg}^{*}$ & Esomeprazole & Pink $^{\ddagger \ddagger}$ & $410 \mathrm{mg} \pm 1.1 \%$ & 224 N (195-242) \\
\hline Nexium 40 mg $^{*}$ & Esomeprazole & Pink $^{\ddagger \ddagger}$ & $576 \mathrm{mg} \pm 1.1 \%$ & $245 \mathrm{~N}(218-274)$ \\
\hline Orfiril Retard" & Sodium valproate & White ${ }^{t+}$ & $654 \mathrm{mg} \pm 0.9 \%$ & $260 \mathrm{~N}(228-283)$ \\
\hline Orfiril 150 mg॥ & Sodium valproate & White $e^{\ddagger \ddagger}$ & $251 \mathrm{mg} \pm 1.7 \%$ & 152 N (145-159) \\
\hline Orfiril 300 mg" & Sodium valproate & White $^{\ddagger \ddagger}$ & $475 \mathrm{mg} \pm 1.0 \%$ & 217 N (199-228) \\
\hline Orfiril 600 mg" & Sodium valproate & White $e^{\ddagger \ddagger}$ & $949 \mathrm{mg} \pm 0.8 \%$ & $230 \mathrm{~N}(206-248)$ \\
\hline Renvela 800 mg" & Sevelamer carbonate & White $^{+\dagger}$ & $1081 \mathrm{mg} \pm 1.2 \%$ & $>300 \mathrm{~N}$ \\
\hline TrioBe ${ }^{* *}$ & $\begin{array}{l}\text { Folic acid, } \\
\text { Cyanocobalamin, } \\
\text { Pyridoxine } \\
\text { hydrochloride }\end{array}$ & Yellow & $499 \mathrm{mg} \pm 0.3 \%$ & $100 \mathrm{~N}(96-105)$ \\
\hline
\end{tabular}

${ }^{*}$ Astra Zeneca Plc, ${ }^{+}$MSD,Inc, ${ }^{\ddagger}$ Pfizer Inc, ${ }^{\S}$ Novartis AG, Desitin Arzneimittel GmbH, "Genzyme Corp, ${ }^{* *}$ Recip $A B,{ }^{\dagger \dagger}$ Film coated tablets, ${ }^{\ddagger \ddagger}$ Gastro-resistant tablets (film coated) 
Figure 1
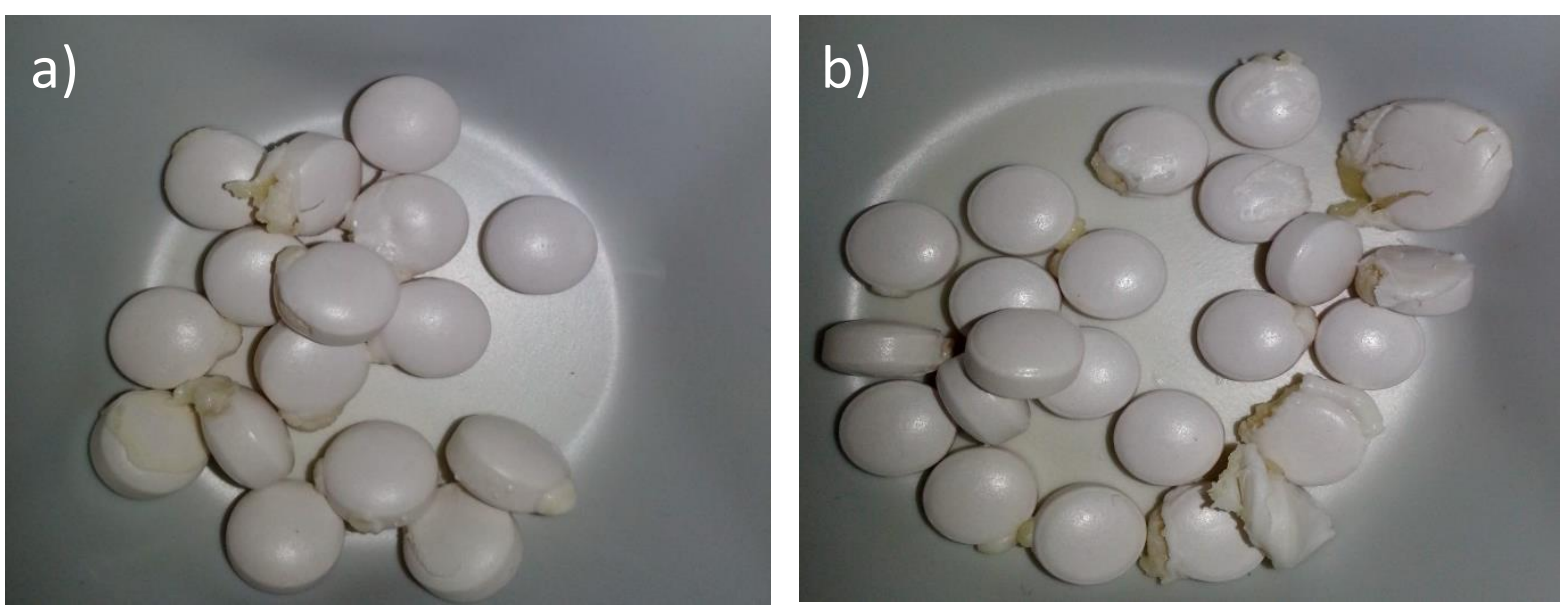
Figure 2:

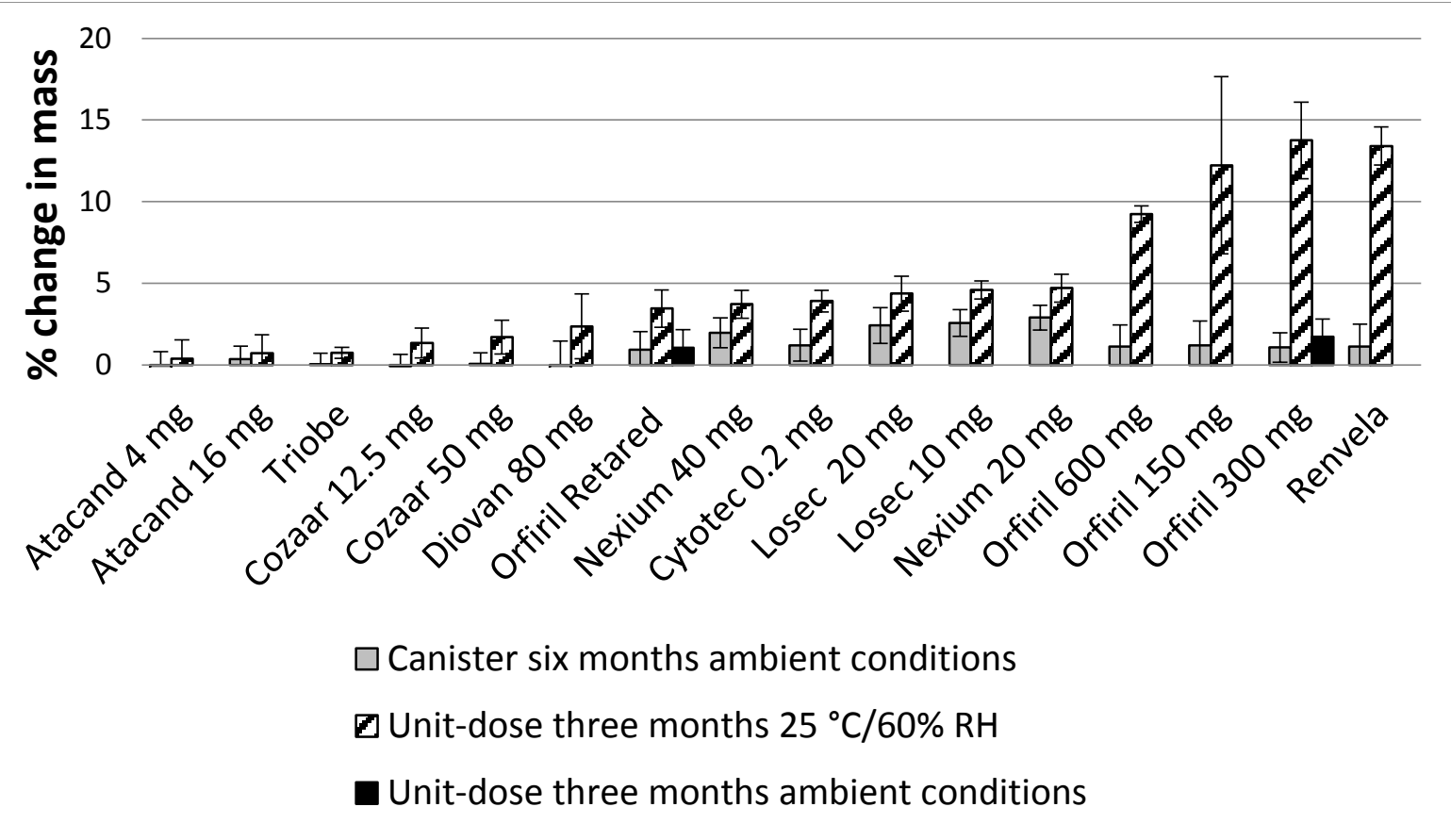


Figure 3:

$\square$ Canister six months ambient conditions $\square$ Unit dose three months $25^{\circ} \mathrm{C} / 60 \% \mathrm{RH}$

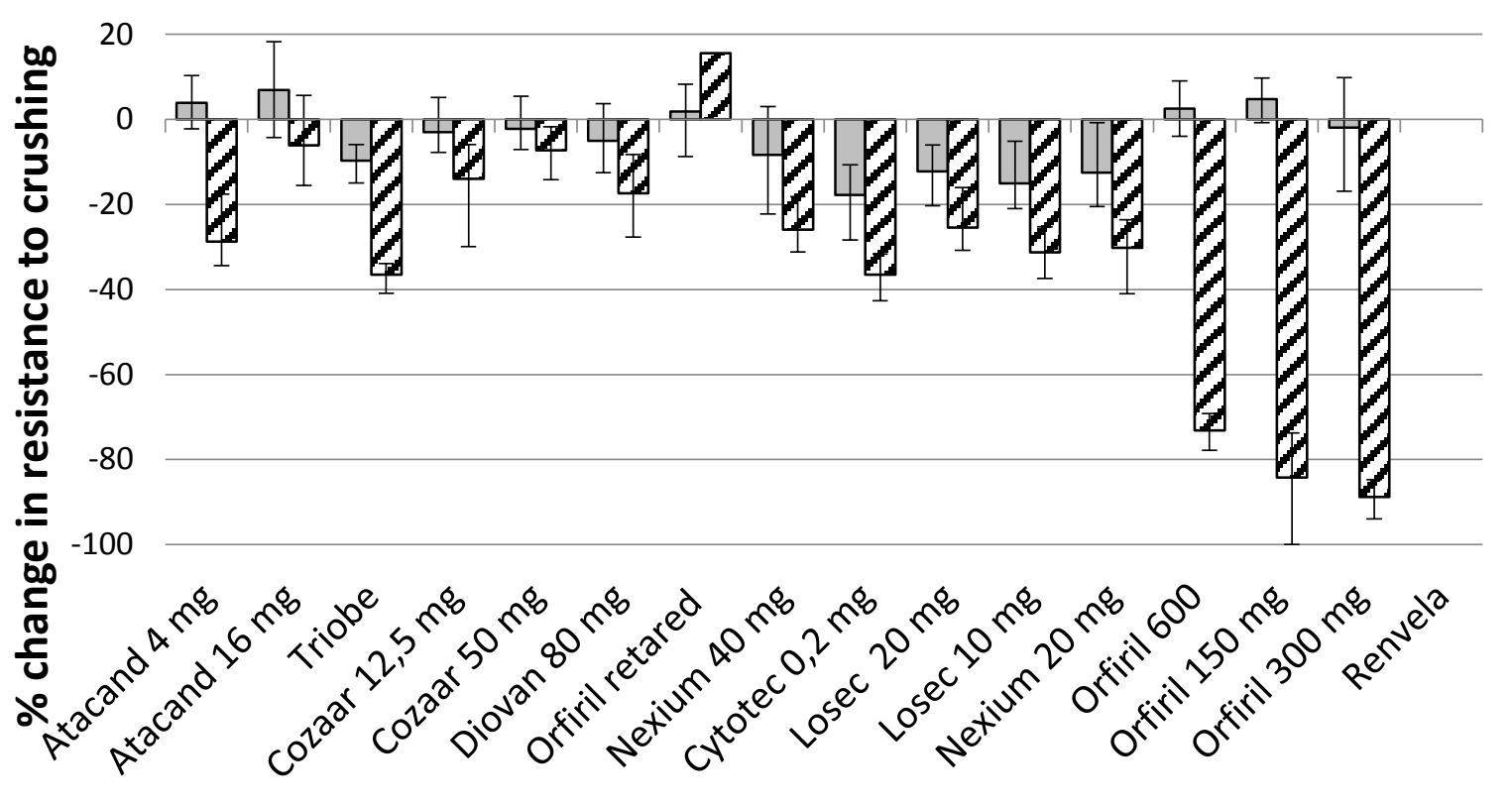

